\title{
Volatility linkages between energy and agricultural commodity prices
}

Brenda López Cabrera* Franziska Schulz*

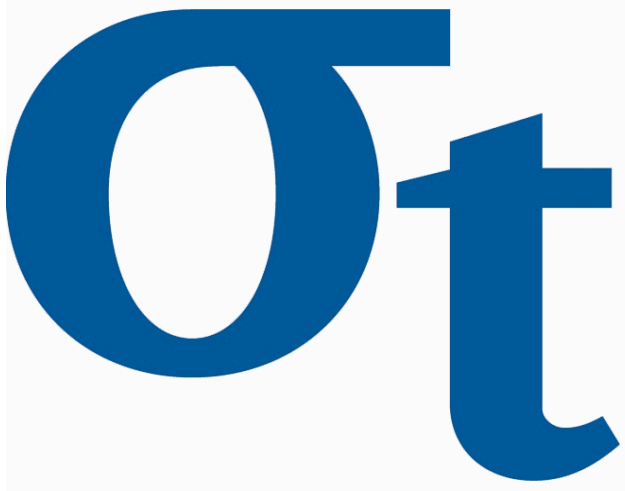

* Humboldt-Universität zu Berlin, Germany

This research was supported by the Deutsche Forschungsgemeinschaft through the SFB 649 "Economic Risk".

http://sfb649.wiwi.hu-berlin.de ISSN 1860-5664 


\title{
Volatility linkages between energy and agricultural commodity prices.*
}

\author{
Brenda López Cabrerał Franziska Schulz ${ }^{\dagger \dagger}$
}

September 11, 2013

\begin{abstract}
In this paper we investigate price and volatility risk originating in linkages between energy and agricultural commodity prices in Germany and study their dynamics over time. We propose an econometric approach to quantify the volatility and correlation risk structure, which has a large impact for investment and hedging strategies of market participants as well as for policy makers. Volatilities and their short and long run linkages (spillovers) are analyzed using a dynamic conditional correlation GARCH model as well as a multivariate multiplicative volatility model. Our approach provides a flexible and accurate fitting procedure for volatility and correlation risk.
\end{abstract}

Keywords: Energy, Agriculture, Biodiesel, Commodities, Interdependencies, Volatility Spillovers

JEL classification: G19, G29, G22, Q14, Q49, Q59

*The financial support from the Deutsche Forschungsgemeinschaft via SFB 649 "Ökonomisches Risiko", Humboldt-Universität zu Berlin is gratefully acknowledged.

${ }^{\dagger}$ Ladislaus von Bortkiewicz Chair of Statistics, Humboldt-Universität zu Berlin

${ }^{\ddagger}$ Corresponding author. E-mail: sulzfran@hu-berlin.de 


\section{Introduction}

Energy is an essential input in the agricultural sector since it is needed e.g. for transportation and processing of food. This creates a linkage between the two sectors. Due to the emergence of large-scale biofuel production in the last years, further linkages between the two sectors arise, since agricultural products are now used as input for energy production. The use of food crops to produce biofuels instead of feeding the world has raised questions about the sustainability of biofuel and put forward the world food security debate. The increasing integration between the markets of energy and agricultural commodities brings into question the effect on the prices in the two markets. Especially in view of the extremely high food prices in recent time and the global food crisis in 2008 the effect of biofuel production is controversially discussed. In public opinion it is often blamed for rising food prices and increasing volatility.

Biodiesel is one of the most common biofuels. It is mainly produced in Europe, where Germany is the largest producer. Today, biodiesel production in Germany is more than twelve times as high as it was in 2002 (LEL, LfL, 2012). The rising production level was mainly fostered by government policies. The introduction of biodiesel was supposed to reduce the dependency on fossil fuel, which is considered desirable due to the limited resources and negative impacts on the environment of fossil fuel. In 2007 a sequentially rising and binding minimum quota was introduced to further promote the use of biodiesel.

The tremendous increase in biodiesel production raises the need for a deeper understanding of its effect on the prices of other markets. Understanding dependencies between prices and their dynamics over time is of high interest for policy makers as well as for market participants in order to hedge against price risk. In this paper we concentrate on linkages in terms of price and volatility risk between energy and agricultural commodity prices in Germany and study their dynamics over time. We aim at answering the question whether linkages as indicator for spillovers exist and how they behave over time.

The link between prices of biofuel and agricultural commodities has been addressed by many researches. Most of them focus on dependencies between the level of prices. To the best of our knowledge, volatility linkages between agricultural commodity prices and biofuel in Germany have not been studied so far. We propose an econometric approach to quantify the volatility and correlations risk structure, which constitutes a great part of price risk and has a larger impact for investment and hedging strategies. To achieve this, weekly spot prices of biodiesel, crude oil and rapeseed are analyzed over a period from 2003 to 2012. We apply a vector error correction model (VECM) in order to filter the data from long run comovement in the level of prices. The VECM yields estimates of the long run and short run relations between the price levels. Volatility and volatility linkages are analyzed using a dynamic conditional correlation (DCC) GARCH model as well as a multiplicative volatility model, recently proposed by Hafner and Linton (2010). The DCC-GARCH model allows to model dynamics in the conditional volatilities and their correlations over time. However, GARCH models are based on the assumption of a constant unconditional covariance matrix. We relax this assumption by ap- 
plying a multiplicative volatility model, which allows a time varying unconditional covariance matrix, where the unconditional variance is modeled in a non-parametric way. It yields estimates of the long run unconditional variances and correlations, providing a more flexible and accurate fitting procedure for volatility and correlation risk. Our analysis reveals that in the long run German biodiesel prices adjust to crude oil and rapeseed prices. Furthermore, we find that the volatility of biodiesel is only weakly linked to the volatility of crude oil and rapeseed, while the linkage between the volatility of rapeseed and crude oil is increasing in recent years.

The remainder of this paper is structured as follows. The next section gives an overview about the German biodiesel market and policies. Section 3 presents recent literature on price transmissions and spillover effects between energy and agricultural markets. Section 4 describes the approach and in section 5 the empirical analysis is conducted on real data. Section 6 concludes. All the computations were carried out in R. The data were obtained from the Bloomberg Professional Service. To simplify notation, dates are denoted with yyyymmdd format.

\section{German biodiesel market and policies}

Biofuel first gained importance after the oil crisis in the 1970's. Due to extremely high prices for fossil fuel in the subsequent years, the demand for alternative fuels arose. The desire to become less dependent on fossil fuel and to obtain a renewable alternative led many governments to introduce programs that supported national production of biofuel.

Biofuels cover a wide range of fuels. The two most common ones are ethanol and biodiesel. Since in the EU diesel was the mostly used transportation fuel during the last decade, the production of biofuel in the EU mainly concentrated on biodiesel, with Germany being the largest producer (30\% of EU production)(EBB, 2008). The production of biodiesel is mainly based on vegetable oil. The most common vegetables used as biodiesel feedstock are soybeans and rapeseed, but also sunflower and soybean oil are utilized (OECD-FAO, 2009). In Germany, about $87 \%$ of biodiesel is produced of rapeseed oil (LEL, LfL, 2012).

Worldwide biodiesel production shows an exponential growth in the last decade. While in 2000 worldwide production was about 0.72 million tons, it increased to 23.6 million tons in 2011. In Germany, biodiesel production strongly increased until 2007, when it amounted to 2,89 million tons compared to 0.22 million tons in 2002. Since 2007 German biodiesel production remained relatively constant and is projected at 2.78 million tons in 2011 (LEL, LfL, 2012).

The large increase in biodiesel production in Germany was mainly encouraged by tax exemptions. In 2006 the Biofuel Quota Act (Biokraftstoffquotengesetz) was passed. It replaced the prevailing tax incentives by a gradually increasing and binding minimum quota of renewable energy in the transport sector. In 2009 minimum quotas were revised and set to $5.25 \%$ in 2009 and to $6.25 \%$ from 2010 onwards (Lamers, 2011). Additionally, since 2009 the minimum content of biodiesel in transport diesel is set to $4.4 \%$ (Sorda, Banse and Kemfert, 2010). While the production of biofuel is on the one hand promoted by many governments around the world, the increasing production level on the other hand raises the question about the 
sustainability of biofuel and its effect on agricultural commodity prices.

\section{Literature Review}

The link between biofuel and agricultural commodity prices has been addressed by an increasing number of researches using econometric methods. Most part of the literature has concentrated on price interdependencies. So far, only few have analyzed volatilities and their transmission between markets. Since Brazil and the U.S. are the leading producers of biofuel, most studies on linkages between biofuel and agricultural commodity prices analyze data from these countries. The empirical quantifications of the European market impact of these risk factors, however, remains to be done.

Balcombe and Rapsomanikis (2008) investigate non-linear adjustment towards long-run equilibrium between crude oil, ethanol and sugar in Brazil using bayesian techniques. They find a long run equilibrium between each price pair. Further, their analysis reveals a causal hierarchy from oil to sugar to ethanol. Similar results are found in the Spanish market by Hassouneh et al. (2012), where the authors apply a parametric VECM as well as a nonparametric multivariate local polynomial regression (MLPR) to sunflower oil, biodiesel and crude oil price data. The results of the VECM suggest that only biodiesel reacts to deviations from the long run equilibrium. However, sunflower oil reacts to short-run price changes of biodiesel. Furthermore, the results of the MLPR reveal that biodiesel adjusts faster to the long-run equilibrium when its price is below the equilibrium price than when it is above the equilibrium price.

In order to allow for changes in the price adjustment behavior of crude oil, rapeseed oil, soy oil and biodiesel due to changing economic and political influences in Germany, Busse et al. (2010b) apply a regime-dependent Markov-switching VECM, which allows the parameters of the model to differ between regimes. They find that in the long run crude oil is the driving force of biodiesel prices and that in turn, biodiesel prices drive vegetable oil prices. Zhang et al. (2009) study price transmissions and volatility spillovers between weekly U.S. ethanol, corn, soybean, gasoline and oil prices using a multivariate BEKK-GARCH model. They authors did not find spillovers from ethanol price volatility to corn and soybean price volatility, but instead discover volatility transmissions from agricultural commodity prices to energy prices.

Volatility spillover effects between the U.S. energy and agricultural market in a more recent time period are analyzed by Trujillo-Barrera et al. (2011). They adopt a VECM-BEKK-GARCH model in which exogenous shocks from the oil market are transmitted to the corn and ethanol market. Results show strong evidence for the existence of linkages from crude oil to corn and ethanol, and spillovers between corn and ethanol, but the direction goes mainly from corn to ethanol. This differs from the findings of Zhang et al. (2009) and therefore indicates that there is an amplified connection between these markets in recent years. A similar approach is applied in Serra et al. (2011), who use a VECM together with a multivariate BEKK-GARCH model in order to analyze price transmissions and volatility spillovers between Brazilian weekly ethanol, crude oil and sugar prices. As Hassouneh et al. (2012), they find 
a long run equilibrium between prices: while ethanol is adjusting to deviations from the long-run equilibrium, crude oil and sugar are exogenous for long-run parameters. However, Serra et al. (2011) find that ethanol price volatility is affected by shocks in the oil and sugar market, which is a different result found in Zhang et al. (2009) found for U.S. market. Serra (2011) extends the results of Serra et al. (2011) by applying a semiparametric multivariate GARCH model proposed by Long et al. (2011), which is robust to potential misspecifications of the error density and of the functional form of the conditional covariance matrix. Their results are in line with the findings of Serra et al. (2011) and Hassouneh et al. (2012).

A drawback of the BEKK specification is that the parameters cannot be easily interpreted and net effects on variances and covariances cannot be seen immediately (Tse and Tsui, 2002). An alternative is the dynamic conditional correlation (DCC) GARCH model, which models the conditional variances as univariate GARCH processes and the conditional correlations as functions of past market shocks, both varying over time (Engle and Sheppard, 2001). The advantage of the model is the intuitive interpretation of parameters (Silvennoinen and Teräsvirta, 2009).

Busse et al. (2010a) analyze linkages between price volatilities in German agricultural and energy markets in a DCC-GARCH framework. The results of the univariate estimation process indicate that the conditional volatility of all return series is affected by own past volatility as well as by own market shocks, with an increasing correlation between rapeseed and crude oil volatility during the sample period. Hence, volatility in the energy market and in the agricultural market develops concurrently, which supports the ideas of an increasing integration between energy and agricultural markets. However, they do not consider comovements in the level of prices. Du and McPhail (2012) investigate dynamic evolutions of ethanol, gasoline and corn prices in the United States with a DCC-GARCH model with structural breaks. The results reveal time varying conditional correlations and variances of the prices can largely be explained by price changes in the other markets. These results are compatible with earlier studies. Zhang et al. (2009) do not find significant integration between the U.S. agricultural and energy markets in the early 2000s. For more recent data however, Trujillo-Barrera et al. (2011) do find an increased strength in the relationship between these markets.

Kristoufek et al. (2012) in contrast to the above papers use a method of taxonomy which enables them to simultaneously analyze price transmissions and correlations of different biofuels and related commodities from different locations. The idea is to create networks by translating correlations of commodities into distances. The results show that before the food crisis in 2008/2009 the commodity prices under consideration were only weakly connected. During and after the food crisis the connections strengthened. However, the directions of the connections cannot be determined using the taxonomy approach.

All studies considered find evidence for a strong level of integration between the markets of oil, biofuel and related agricultural commodities, which is increasing in recent years. However, the evidence for an effect of biofuel prices on the level and volatility of agricultural commodity prices is limited. Especially for the German market, to the best of our knowledge, there exists no study on volatility linkages between agricultural commodity prices and biofuel. 


\section{Methodology}

Commodity price series share some characteristic time series properties that have to be considered in a sound statistical analysis: (i) high volatility, (ii) stochastic trends, (iii) comovement in commodity price series and (iv) time-varying volatility (Myers, 1994). Considering these properties, one has to be careful when specifying the mean and the variance of the price series. Our proposed methodology is based on a two stage procedure. First, the mean is specified with a vector error correction model (VECM). Thereby, we filter the price series from comovements in their conditional mean. In the second stage we model volatilities and volatility transmissions via a multivariate GARCH model as well as by a more general multivariate multiplicative volatility model.

\subsection{Vector error correction model (VECM)}

The characteristic comovement of commodity price series is addressed by the concept of cointegration, which was introduced by Granger (1981). The idea behind cointegration is that though individual price series are non-stationary, a linear combination of price series might be stationary. Engle and Granger (1987) formalized the idea of cointegration for vectors with components that are all integrated of the same order. Campbell and Perron (1991) generalized the definition to vectors with components that are allowed to be integrated of different orders: an $(n \times 1)$ vector of variables $p_{t}$ is said to be cointegrated if at least one nonzero n-element vector $\beta_{i}$, namely the cointegrating vector, exists such that $\beta_{i}^{\top} p_{t}$ is trend stationary. If $r$ such linearly independent vectors $\beta_{i}(i=1, \ldots, r)$ exist, we say that $p_{t}$ is cointegrated with cointegration rank $r$. We define the $(n \times r)$-matrix of cointegrating vectors $\beta=\left(\beta_{1}, \ldots, \beta_{r}\right)$. The $r$ elements of the vector $\beta^{\top} p_{t}$ are trend-stationary and $\beta$ is called the cointegrating matrix.

In the vector error correction model (VECM) changes in the vector $p_{t}$ depend on deviations from such a long run equilibrium relationship as well as on short term dynamics, the VECM of order 1 is defined as

$$
\begin{aligned}
\Delta p_{t} & =c+\Pi p_{t-1}+\Gamma \Delta p_{t-1}+u_{t} \\
& =c+\alpha \beta^{\top} p_{t-1}+\Gamma \Delta p_{t-1}+u_{t}
\end{aligned}
$$

where $\Delta$ is a first difference operator, such that $\Delta p_{t}=p_{t}-p_{t-1}$ denotes the change in the vector $p$ from time $t-1$ to time $t$ (short term price changes), $c$ is a constant, $\beta^{\top} p_{t-1}$ is the cointegration relation and describes a long run equilibrium, $\alpha$ gives the speed of adjustment with which prices return to the long run equilibrium, $\Gamma$ measures reactions to short term price changes, whereas $u_{t}$ is an error term which captures potential GARCH effects.

The parameters of the VECM are estimated by quasi maximum likelihood (QML) under the assumption of homoscedastic errors. This enables us to estimate VECM parameters and GARCH parameters separately. Under the presence of heteroscedasticity estimation results are still consistent (Bauwens et al., 2012). The normal 
density based QMLE is defined as maximizing

$$
\begin{aligned}
\mathcal{L}(\theta) & =-\frac{T n}{2} \log (2 \pi)-\frac{T}{2} \log |\Sigma|-\frac{1}{2} \sum_{t=1}^{T} u_{t}^{\top} \Sigma^{-1} u_{t} \\
\text { with } u_{t} & =\Delta p_{t}-c-\alpha \beta^{\top} p_{t-1}-\Gamma \Delta p_{t-1},
\end{aligned}
$$

where $\theta$ denotes the parameters of the model and $\Sigma$ is the unconditional covariance matrix of $u_{t}$ (Hamilton, 1994).

\subsection{Multivariate GARCH model (MGARCH)}

Let $u_{t}$ be a $n$-variate vector of $T$ observations with $\mathrm{E}\left(u_{t} \mid \mathcal{F}_{t-1}\right)=0$, where $\mathcal{F}_{t-1}$ is a sigma field generated by the past information until time $t-1$. In the following we will assume that $u_{t}$ is a vector of VECM residuals. The estimation of the dynamics of the conditional covariance matrix of $u_{t}$ is carried out within the framework of the multivariate GARCH (MGARCH) model:

$$
u_{t}=H_{t}^{1 / 2} z_{t}, \quad z_{t} \sim \operatorname{iid}\left(0, \mathrm{I}_{n}\right), \quad t=1,2, \ldots, T,
$$

where $H_{t}^{1 / 2}$ is a $n \times n$ positive definite matrix such that $H_{t}^{1 / 2}\left(H_{t}^{1 / 2}\right)^{\top}=H_{t}$ and $H_{t}=\operatorname{Var}\left(u_{t} \mid \mathcal{F}_{t-1}\right)$ is the covariance matrix of $u_{t}$ conditional on the sigma field $\mathcal{F}_{t-1}$. Several specifications for $H_{t}$ are proposed in the literature, for an overview see Bauwens et al. (2006) or Silvennoinen and Teräsvirta (2009).

Suppose now that the conditional covariance matrix can be decomposed into conditional variances and a conditional correlation matrix, which can be specified separately, via the dynamic conditional correlation (DCC) model proposed by Engle and Sheppard (2001):

$$
\begin{aligned}
H_{t} & =D_{t} R_{t} D_{t} \\
D_{t} & =\operatorname{diag}\left(h_{11 t}^{1 / 2}, \ldots, h_{n n t}^{1 / 2}\right) \\
R_{t} & =\left(\mathrm{I}_{n} \odot Q_{t}\right)^{-1 / 2} Q_{t}\left(\mathrm{I}_{n} \odot Q_{t}\right)^{-1 / 2} \\
Q_{t} & =(1-a-b) \bar{Q}+a \xi_{t-1} \xi_{t-1}^{\top}+b Q_{t-1},
\end{aligned}
$$

where $\odot$ denotes the Hadamard product, $\xi_{i t} \stackrel{\text { def }}{=} u_{i t} / \sqrt{h_{i i t}}(i=1, \ldots, n)$ are the residuals $u_{t}$ standardized by their conditional standard deviations, $\bar{Q}$ is the unconditional covariance matrix of $\xi_{t}$ and $a$ and $b$ are non-negative scalar parameters satisfying $a+b<1$. $D_{t}$ is the diagonal matrix of time varying standard deviations from univariate GARCH processes and $R_{t}$ is the time varying conditional correlation matrix. Recall that DCC can be viewed as a nonlinear combination of univariate GARCH models.

The DCC model was designed to allow for a two stage estimation procedure. In the first stage, the conditional variances are estimated using a univariate GARCH specification. In the second stage, the standardized residuals (residuals divided by the the estimated standard deviations from the first stage) are used to estimate the parameters of the dynamic correlations. By assuming $z_{t}$ in (3) to be normally 
distributed, consistent estimates can be obtained by a two stage quasi-maximum likelihood (QML) procedure. The log likelihood function of the model is given by

$$
\mathcal{L}(\theta)=-\frac{1}{2} \sum_{t=1}^{T}\left\{n \log (2 \pi)+\log \left(\left|D_{t} R_{t} D_{t}\right|\right)+u_{t}^{\top} D_{t}^{-1} R_{t}^{-1} D_{t}^{-1} u_{t}\right\},
$$

where $\theta$ denotes the set of parameters of the model, i.e. parameters of the univariate variances $\psi$ and parameters of the conditional correlations $\phi$. In the first step $R_{t}$ is replaced by an identity matrix of size $n$. This yields the first step log likelihood function:

$$
\begin{aligned}
\mathcal{L}_{1}(\psi) & =-\frac{1}{2} \sum_{t=1}^{T}\left\{n \log (2 \pi)+2 \log \left(\left|D_{t}\right|\right)+\log \left(\left|\mathrm{I}_{n}\right|\right)+u_{t}^{\top} D_{t}^{-1} \mathrm{I}_{k} D_{t}^{-1} u_{t}\right\} \\
& =-\frac{1}{2} \sum_{t=1}^{T}\left\{n \log (2 \pi)+2 \log \left(\left|D_{t}\right|\right)+u_{t}^{\top} D_{t}^{-2} u_{t}\right\} \\
& =-\frac{1}{2} \sum_{i=1}^{n}\left[T \log (2 \pi)+\sum_{t=1}^{T}\left\{\log \left(h_{i t}\right)+\frac{u_{i t}^{2}}{h_{i t}}\right]\right\},
\end{aligned}
$$

which is the sum of log-likelihoods of univariate GARCH equations (Engle and Sheppard, 2001). The univariate GARCH equations can be specified in various ways. In our analysis we apply an exponential GARCH (EGARCH) model introduced by Nelson (1991). The EGARCH model allows for asymmetric responses to shocks and does not require any parameter restrictions. It is given by

$$
\log \left(h_{i i t}\right)=\omega_{i}+\alpha_{i}\left\{\left|\frac{u_{i t-1}}{h_{i i t-1}}\right|-\mathrm{E}\left(\left|\frac{u_{i t-1}}{h_{i i t-1}}\right|\right)\right\}+\gamma_{i} \frac{u_{i t-1}}{h_{i i t-1}}+\beta_{i} \log \left(h_{i i t-1}\right),
$$

where $i=1, \ldots, n$. $\alpha_{i}, \beta_{i}, \gamma_{i}$ and $\omega_{i}$ are scalar parameters to be estimated. The parameter $\alpha_{i}$ is a symmetric measure of the GARCH effect, that is it indicates how much the conditional volatility is affected by the magnitude of past shocks. $\gamma_{i}$ measures the asymmetry of the model, $\beta_{i}$ measures the persistence of past conditional volatility and $\omega_{i}$ is a constant. In the second step, (8) is estimated conditional on the parameter estimates obtained in the first step. The QMLE is given by maximizing

$$
\begin{aligned}
\mathcal{L}_{2}(\phi \mid \psi) & =-\frac{1}{2} \sum_{t=1}^{T}\left\{n \log (2 \pi)+\log \left(\left|D_{t} R_{t} D_{t}\right|\right)+u_{t}^{\top} D_{t}^{-1} R_{t}^{-1} D_{t}^{-1} u_{t}\right\} \\
& =-\frac{1}{2} \sum_{t=1}^{T}\left\{n \log (2 \pi)+2 \log \left(\left|D_{t}\right|\right)+\log \left(\left|R_{t}\right|\right)+\xi_{t}^{\top} R_{t}^{-1} \xi_{t}\right\} \\
& =\text { constant }-\frac{1}{2} \sum_{t=1}^{T}\left\{\log \left(\left|R_{t}\right|\right)+\xi_{t}^{\top} R_{t}^{-1} \xi_{t}\right\}
\end{aligned}
$$

\subsection{Multivariate multiplicative volatility model (mMGARCH)}

A core assumption of MGARCH models is that the unconditional covariance matrix $\Sigma$ is constant over time. In order to relax this assumption Bauwens et al. (2012) 
developed a multiplicative volatility model which allows for smooth changes in the unconditional covariance matrix through a multiplicative component. The idea is to decompose the unconditional covariance matrix of $u_{t}, \Sigma$ into a long run component and a short run component. The long run component is a smooth function of time and corresponds to the unconditional covariance. The short run component captures potential dynamics of multivariate GARCH processes. The model is defined as:

$$
\begin{aligned}
H_{t} & =\Sigma(\tau)^{1 / 2} G_{t}^{1 / 2}\left(G_{t}^{1 / 2}\right)^{\top}\left\{\Sigma(\tau)^{1 / 2}\right\}^{\top} \\
& =\Sigma(\tau)^{1 / 2} G_{t}\left\{\Sigma(\tau)^{1 / 2}\right\}^{\top}
\end{aligned}
$$

where $\tau=\frac{t}{T}$. By assuming $\mathrm{E}\left(G_{t}\right)=\mathrm{I}_{n}$ for identification, it follows that

$$
\operatorname{Var}\left(u_{t}\right)=\Sigma(\tau)^{1 / 2} \mathrm{E}\left(G_{t}\right)\left\{\Sigma(\tau)^{1 / 2}\right\}^{\top}=\Sigma(\tau)
$$

Hence, $\Sigma(\tau)$ is the unconditional covariance matrix of $u_{t}$. It captures the long run dynamics and is a deterministic and smooth function of time.

Let $\varepsilon_{t} \stackrel{\text { def }}{=} \Sigma(\tau)^{-1 / 2} u_{t}$ be the vector of residuals standardized by its unconditional covariance. It follows that $\operatorname{Var}\left(\varepsilon_{t}\right)=\mathrm{I}_{n}$ and $\operatorname{Var}\left(\varepsilon_{t} \mid \mathcal{F}_{t-1}\right)=G_{t}$. Hence, $\varepsilon_{t}$ is a vector with a constant unconditional covariance matrix and with $G_{t}$ as its conditional covariance matrix. In case the standardized residuals $\varepsilon_{t}$ show $\mathrm{ARCH}$ effects, they can be modeled using a multivariate GARCH model as described in the previous section. Due to the standardization, they fulfill the assumption of a constant unconditional covariance matrix.

Following Hafner and Linton (2010), the unconditional covariance matrix $\Sigma(\tau)$ can estimated efficiently by the nonparametric Nadaraya-Watson estimator:

$$
\Sigma(\tau)=\frac{\sum_{t=1}^{T} K_{h}\left(\tau-\frac{t}{T}\right) u_{t} u_{t}^{\top}}{\sum_{t=1}^{T} K_{h}\left(\tau-\frac{t}{T}\right)}
$$

where $\tau=\frac{1}{T}, \frac{2}{T}, \ldots, 1, K_{h}($.$) is a kernel function and h$ is a positive bandwidth parameter. The bandwidth parameter can be selected using a likelihood crossvalidation criterion as proposed by Yin et al. (2010):

$$
C V(h)=\frac{1}{n} \sum_{t=1}^{T}\left[u_{t}^{\top} \Sigma_{(-t)}^{-1}\left(\frac{t}{T}\right) u_{t}+\log \left\{\left|\Sigma_{(-t)}\left(\frac{t}{T}\right)\right|\right\}\right],
$$

where $\Sigma_{(-t)}$ is the leave-one-out estimator of the unconditional covariance matrix. That is, it is estimated as (14), but with the $t$-th observation left out. The optimal bandwidth is determined by minimizing (15).

\section{$5 \quad$ Empirical analysis}

\subsection{Data}

The empirical analysis utilizes weekly prices of biodiesel $p_{b(t)}$, crude oil $p_{c(t)}$ and rapeseed oil $p_{r(t)}$ from 20030523 to 20120424 . This amounts to a total of $467 \mathrm{ob}-$ servations. All prices are expressed in Euros per cubic meter. The Data was taken 
from the database Bloomberg, the corresponding tickers and contract specifications are given in Table 1. Biodiesel prices are German consumer prices at the pump. Crude Oil prices are spot prices of European brent blend crude oil. Spot prices of rapeseed oil are not directly observable. However, several future prices with different maturities are available. We took futures traded at LIFFE-Paris, which operates the MATIF (Marché à Terme International de France) and which is the most important stock exchange for rapeseed worldwide (Busse et al., 2010a). The delivery months are February, May, August and November. As suggested by Liu et al. (2012), the futures prices can be used to infer the spot prices by applying the spot-future relation of commodities. The spot price $p_{t}$ is computed as

$$
p_{t}=F_{t}^{T_{1}} / \exp \left\{\left(T_{1}-t\right) \log \left(\frac{F_{t}^{T_{2}}}{F_{t}^{T_{1}}}\right) \frac{1}{T_{2}-T_{1}}\right\},
$$

where $T_{1}<T_{2}$ are two maturities and $F_{t}^{T_{1}}, F_{t}^{T_{2}}$ the corresponding futures prices.

\begin{tabular}{lll}
\hline \hline Commodity & Ticker & Contract type \\
\hline Cude oil & EUCRBREN Index & Spot, Europe \\
Rapeseed & IJ Comdty & Futures, LIFFE Paris \\
Biodiesel & BIOCEUGE Index & Spot, Germany \\
\hline \hline
\end{tabular}

Table 1: Analyzed Bloomberg Commodities

\begin{tabular}{lccc}
\hline \hline & Crude Oil $p_{c}$ & Rapeseed $p_{r}$ & Biodiesel $p_{b}$ \\
\hline Mean & 335.14 & 525.31 & 1070.36 \\
Standard Deviation & 116.65 & 154.38 & 193.71 \\
\hline & \multicolumn{3}{c}{ Correlation } \\
\hline Crude Oil $p_{c}$ & 1 & 0.817 & 0.909 \\
Rapeseed $p_{r}$ & & 1 & 0.818 \\
Biodiesel $p_{b}$ & & & 1 \\
\hline \hline
\end{tabular}

Table 2: Descriptive Statistics (prices in Euro $/ \mathrm{m}^{3}$ ) for the period 20030523 to 20120424.

Figure 1 shows the spot price series of the analyzed commodities. Descriptive statistics are given in Table 2. The plot shows that prices peaked during the global food crisis in $2007 / 2008$, decreased afterwards, but went up again in 2011 . The decrease in prices corresponds to the late-2000s recession, where the overall level of commodity prices decreased. The increase in food prices in 2009/2010 with its peak in 2011 is mainly attributed to production shortfalls due to bad weather conditions. However, also structural problems that already triggered the global food crisis in 2007/2008 persist. Some of these are an increasing demand due to a steadily increasing world population and an increasing demand for meat products. Additionally, the need of feedstock for the production of biofuel causes a decline in food supply and an increased competition for agricultural land (Rathmann et al., 2010). Another, though 


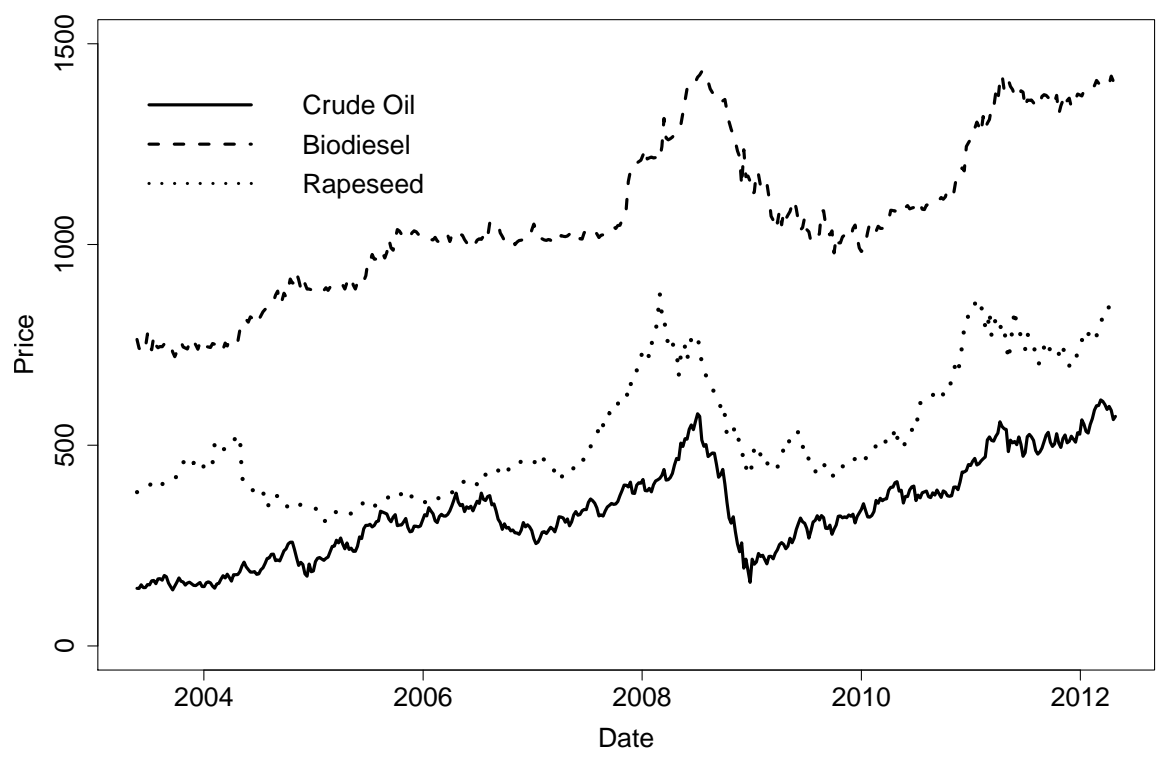

Figure 1: Weekly prices of Crude Oil (solid line), Rapeseed (dot line) and Biodiesel (dashed lin) in $€ / m^{3}$

ambiguous explanation often given for the sharp increase in prices is speculative activity in commodity price markets. Ghosh (2010) argues that price movements of the size as realized during the food crisis could not have been created solely by real supply and demand changes. The actual function of speculators in the market is to predict price patterns and thereby stabilize the market, reduce price volatility and ensure liquidity. Therefore, the presence of speculators in the market does not harm the market per se. However, excessive speculation and a lack of regulations can lead to prices that do not reflect demand and supply anymore. Headey and Fan (2008) though point out that higher prices induce speculation and therefore, it is hard to determine causality.

For the statistical analysis of the data logarithmic transformations are taken in order to obtain well-behaved errors. Additionally, using logarithmic prices facilitates interpretation of results, since coefficients correspond to percentage changes and therefore, can be interpreted as price elasticities Serra et al. (2011). Missing data points are interpolated using cubic splines. Seasonal effects in the data are removed using a local linear regression function (LLR) as suggested by Härdle et al. (2011). The seasonal effect of week $t(t=1, \ldots, 52)$ is defined as

$$
\Lambda_{t}=\underset{a, b}{\arg \min } \sum_{i=1}^{52}\left\{\bar{p}_{i}-a-b(i-t)\right\}^{2} K_{h}(i-t),
$$

where $\bar{p}_{i}$ is the mean over years of weekly prices, $K_{h}($.$) is a kernel function and h$ a positive bandwidth parameter. We use a Gaussian kernel and choose the bandwidth as proposed by Bowman and Azzalini (1997). The following analysis is based on deseasonalized data. All estimates are in-sample estimates. 


\subsection{Results}

\subsubsection{Unit root and cointegration tests}

In order to test for the presence of a unit root against the alternative of a stationary process in the price series of crude oil, biodiesel and rapeseed the Augmented Dickey Fuller (ADF) test as well as the KPSS test proposed by Kwiatkowski et al. (1992) are conducted. The test statistic of both tests are given in Table 3. The ADF test gives evidence for the presence of a unit root in all three price series. The existence of a trend or a drift is rejected for all series. In the KPSS test, the null of a stationary process is rejected in all three price series. Hence, the results of the KPSS test are in line with the results of the ADF test.

\begin{tabular}{lccc|cc}
\hline \hline & \multicolumn{3}{c}{ ADF Test } & \multicolumn{2}{c}{ KPSS Test } \\
\hline & Test Statistic 5\% Critical Value Lags & Test Statistic 5\% Critical Value \\
\hline Crude Oil & -1.9247 & -1.95 & 9 & 1.7604 & 0.463 \\
Biodiesel & -1.2033 & -1.95 & 9 & 1.9467 & 0.463 \\
Rapeseed & -0.7881 & -1.95 & 8 & 1.6586 & 0.463 \\
\hline \hline
\end{tabular}

Table 3: Results of the Augmented Dickey Fuller Test and the KPSS test

\begin{tabular}{lccc}
\hline \hline$H_{0}$ & $H_{a}$ & Test Statistic & $5 \%$ Critical Value \\
\hline $\mathrm{r}=0$ & $\mathrm{r}>0$ & 39.27 & 31.52 \\
$\mathrm{r} \leq 1$ & $\mathrm{r}>1$ & 7.66 & 17.95 \\
$\mathrm{r} \leq 2$ & $\mathrm{r}>2$ & 1.51 & 8.18 \\
\hline \multicolumn{4}{c}{ Cointegration relation $\beta^{\top} p_{t}:$} \\
& $p_{b(t)}=0.443 p_{c(t)}+0.125 p_{r(t)}$ \\
\hline \hline
\end{tabular}

Table 4: Johansen trace test for cointegration

The cointegration rank $r$ is determined using the Johansen trace test described by Johansen (1995). In order to apply the test, it is useful to know the lag length of the VECM. A lag-structure analysis based on the Hannan Quinn information criterion (HQ) is conducted, which yields a consistent estimate of the lag length Lütkepohl (2005), suggesting an optimal lag order of 1 . According to the results of the Johansen trace test, there exists of a single cointegration relation. The corresponding test statistics as well as the cointegration relationship are given in Table 4 . The results suggest that there exists a long run relationship between crude oil, biodiesel and rapeseed. The parameters indicate that biodiesel is positively related with crude oil and rapeseed in the long run. When biodiesel or rapeseed prices change by $10 \%$, biodiesel prices change by $4.43 \%$ and $1.25 \%$ respectively. The positive long run link between biodiesel and rapeseed is not surprising, since biodiesel production costs largely depend on the price of its feedstock. The positive link between biodiesel and crude oil may on the one hand arise due to the fact that biodiesel serves as a substitute for petroleum diesel that comes from refined crude oil. Hence, if crude 
oil prices rise and as a result also petroleum diesel prices, the demand for biodiesel increases which causes an increase in biodiesel prices. On the other hand, the long run link in prices is further strenghtened through blending obligations, which demand that at least $6.25 \%$ of transportation fuel sold comes from biofuel. The results are compatible with the findings of Balcombe and Rapsomanikis (2008), Serra et al. (2011) and Hassouneh et al. (2012).

\subsubsection{VECM estimation}

Deviations from the long run equilibrium as well as short run dynamics are captured in the VECM. The estimation results of the VECM are shown in Table 5. Since we have weekly data, the estimates correspond to percentage changes from one week to the next. The estimates indicate that at a $5 \%$ significance level only biodiesel reacts to deviations from the cointegration relation, while crude oil and rapeseed are exogenous with respect to the long run relationship. The adjustment coefficient of rapeseed is significant only at a $10 \%$ significance level and is about two third the size of the adjustment coefficient of biodiesel. Hence, if at all, rapeseed adjusts much slower to deviations from the long run equilibrium than biodiesel. This can be explained by the fact that crude oil and rapeseed are traded on the world market, while biodiesel is traded mainly domestically. Crude oil is also exogenous to short term price changes and is only affected by market shocks, which indicates that the crude oil market is efficient. Rapeseed prices, when regarding a 5\% significance level, are affected by own lagged prices, but not by crude oil or biodiesel prices. Biodiesel in contrast, in the short run reacts to changes in crude oil as well as to own lagged prices. Hence, although there exists a long run link between the prices of biodiesel, crude oil and rapeseed, biodiesel does not influence rapeseed and crude oil prices in the short run and only has a limited capacity to influence rapeseed in the long run. Biodiesel prices rather react to price changes in the other two markets. This is compatible with the findings of Hassouneh et al. (2012) in the Spanish market. However, they find that rapeseed reacts to biodiesel price changes in the short run.

\begin{tabular}{lccccl}
\hline \hline & $c$ & $\beta^{\top} p_{t-1}$ & $\Delta p_{c(t-1)}$ & $\Delta p_{r t-1}$ & $\Delta p_{b t-1}$ \\
\hline$\Delta p_{c(t)}$ & 0.0024 & -0.0023 & -0.0513 & 0.0801() & 0.2183 \\
& $(0.0143)$ & $(0.0143)$ & $(0.0503)$ & $(0.0871)$ & $(0.1390)$ \\
$\Delta p_{r(t)}$ & 0.0014 & $0.0153^{*}$ & -0.0312 & $0.1392^{* * *}$ & 0.0078 \\
& $(0.0013)$ & $(0.0081)$ & $(0.0284)$ & $(0.0473)$ & $(0.0492)$ \\
$\Delta p_{b(t)}$ & $0.0011^{*}$ & $0.0239^{* * *}$ & $0.0731^{* *}$ & $0.0548^{* * *}$ & -0.0705 \\
& $(0.0007)$ & $(0.0044)$ & $(0.0156)$ & $(0.0270)$ & $(0.0431)$ \\
\hline \hline
\end{tabular}

Table 5: Estimates of the VECM. *, **, *** Statistically significant at the 10\%, 5\% and $1 \%$ significance level. 


\subsubsection{Multivariate GARCH model estimation}

Figure 2 shows the residuals of the VECM. The picture suggests the presence of volatility clustering. To confirm this, the residuals of the VECM are tested for autocorrelation and GARCH effects. The autocorrelation function (ACF) and partial autocorrelation function (PACF) suggest that the residuals are not autocorrelated. The ACF and PACF are depicted in Figure 3. This is supported by the results of the Ljung-Box test for autocorrelation. However, the ACF and PACF of squared residuals give evidence for autocorrelation as it can be seen in Figure 4. Again, the results of the Ljung-Box test support this finding. Hence, the suspected existence of GARCH effects in the residuals is confirmed.
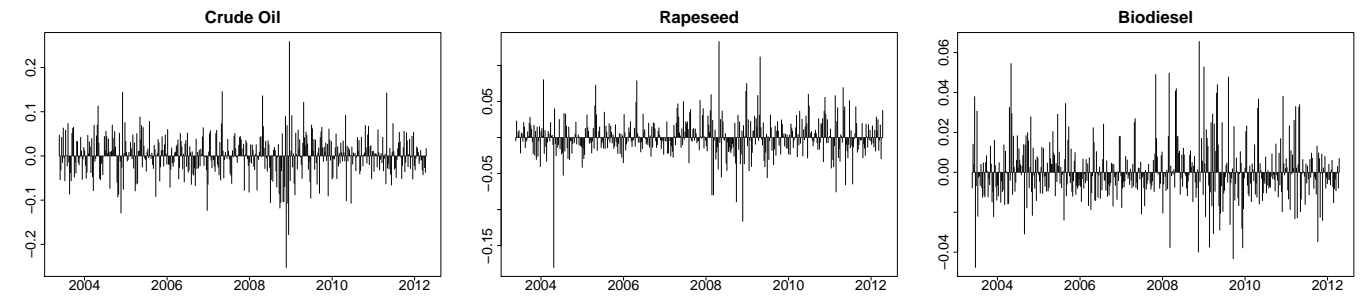

Figure 2: VECM residuals.

In order to model the GARCH effects, the multivariate GARCH model described in section 3 is utilized. Several specifications for the univariate GARCH equations were tried, however, the exponential GARCH model fits the data best. Tests for normality reveal that the VECM residuals are not normally distributed. Though the QMLE are still consistent, non-normality of the residuals causes inefficiency. Therefore, we additionally estimate the parameters under the assumption that the residuals follow a generalized error distribution (GED). The GED contains the normal distribution as a special case, and many other distributions with thinner and thicker tails. The distribution depends on the parameter $\nu$, which determines the thickness of tails and it is estimated together with the other parameters of the MGARCH model. If $\nu=2$ the GED equals the standard normal distribution. $\nu<2$ implies a distribution with thicker tails than the standard normal distribution and $\nu>2$ implies a thinner tailed distribution.

\begin{tabular}{c|cc|cc|cc}
\hline \hline & \multicolumn{3}{|c|}{ Box-Ljung Test } & \multicolumn{2}{c}{ Shapiro-Wilk Test } \\
& \multicolumn{2}{|c|}{ Residuals } & \multicolumn{2}{c}{ Squared residuals } & \multicolumn{2}{c}{ Residuals } \\
\hline & Test Statistic p-Value & Test Statistic p-Value & Test Statistic p-Value \\
Crude oil & 24.46 & 0.22 & 97.44 & $<0.001$ & 0.96 & $<0.001$ \\
Rapeseed & 20.79 & 0.41 & 28.81 & 0.001 & 0.93 & $<0.001$ \\
Biodiesel & 15.46 & 0.74 & 22.44 & 0.013 & 0.95 & $<0.001$ \\
\hline \hline
\end{tabular}

Table 6: Box-Ljung test for autocorrelation of VECM residuals (10 lags included) and squared VECM residuals (20 lags included) and Shapiro-Wilk test for normality of VECM residuals 

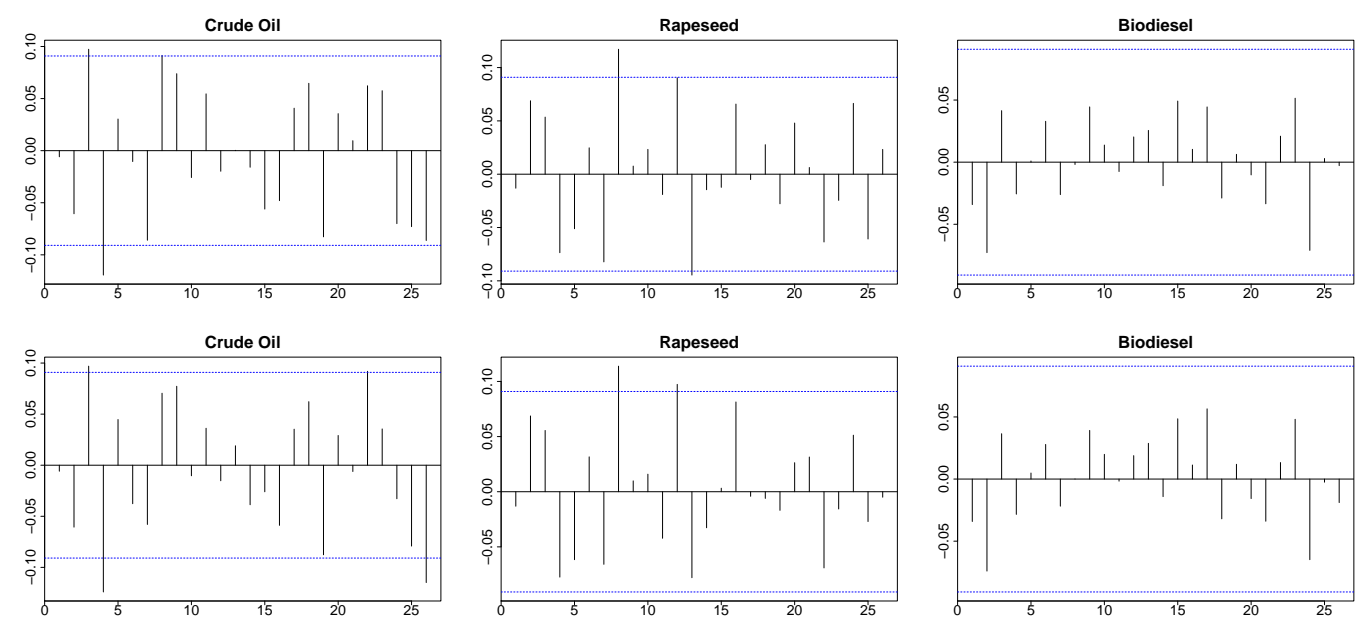

Figure 3: ACF (upper panel) and PACF (lower panel) of VECM residuals.
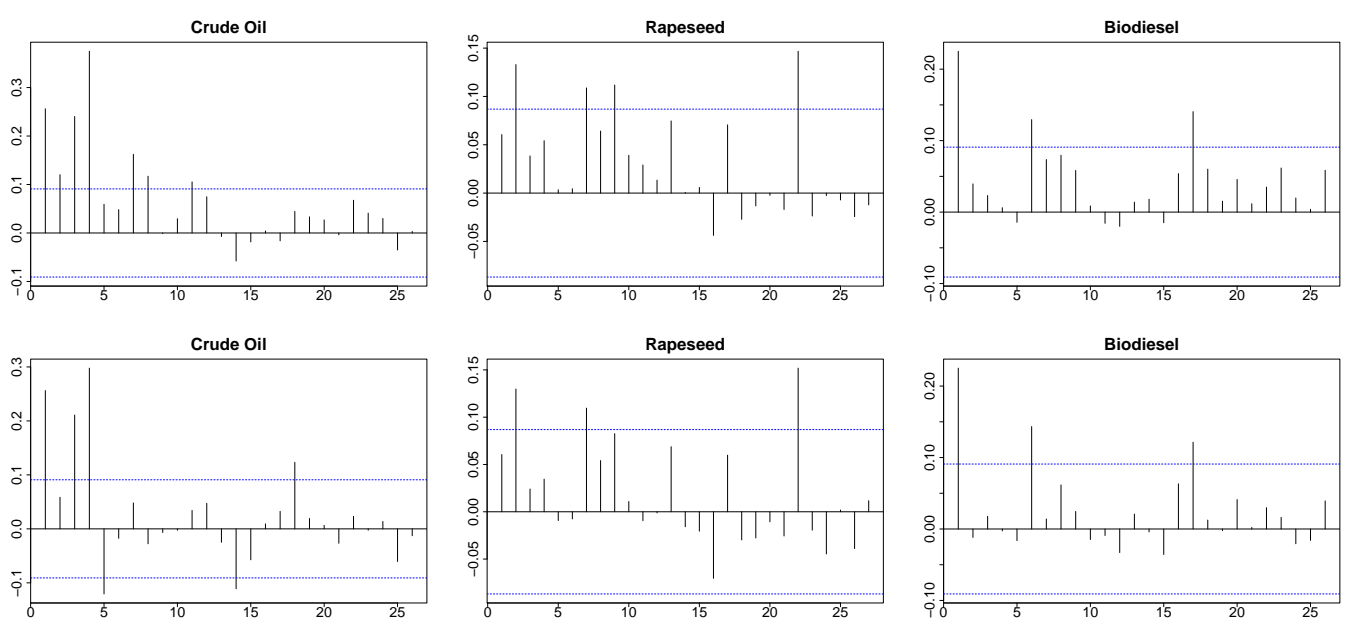

Figure 4: ACF (upper panel) and PACF (lower panel) of squared VECM residuals.

The normality based QML estimates of the MGARCH model are given in Table 7. Table 8 shows the estimates under the assumption of a GED. The results differ only slightly. The tail-thickness parameter $\nu$ is significant different from 2 for all three univariate GARCH processes. This indicates that the distribution of the residuals is thicker tailed than the standard normal distribution, which is in line with the results of the Shapiro-Wilk test, Table ??. Therefore, in the following we will concentrate on the results under the assumption of a GED.

For crude oil, the GARCH parameter $\alpha$ is significant at a $5 \%$ level and negative. This implies that market shocks have a negative impact on volatility. At the same time, the asymmetry measure $\gamma$ is insignificant at a $5 \%$ significance level. This suggests that positive and negative shocks reduce the volatility equally. For rapeseed and biodiesel, the GARCH paramter $\alpha$ is insignificant, while the asymmetry measure $\gamma$ is positive and significant at a $5 \%$ and $10 \%$ significance level, respectively. 
This suggests that positive shocks increase volatility, while negative shocks decrease volatility. The persistence coefficients $\beta$ are significant and close to one for crude oil and biodiesel. A persistence coefficient close to one implies a high degree of persistency in the volatility. This means that high volatility today implies high volatility in the future. The estimated $\beta$ for biodiesel is only about 0.44 , which suggests that shocks in the volatility of biodiesel do persist much shorter than shocks in the other two markets. The DCC model estimates indicate that shocks in the market do not have an effect on correlations. The persistence measure is significant and close to one, indicating that correlations are highly dependent on past correlations.

A plot of the estimated conditional variances can be found in Figure 5. The volatilities show strong time-varying behavior. Furthermore, the differences in the persistency coefficient is clearly visible. While the volatility of crude oil and rapeseed is changing more gradually, the volatility of biodiesel fluctuates heavily. The conditional variance of crude oil is largest in 2008. It reaches a historically high level during the sample period and returns relatively fast to its initial level. Rapeseed shows high volatility in phases of high price levels. This corresponds to the finding that rapeseed volatility increases with positive market shocks and that shocks are highly persistent. The volatility of biodiesel is very unstable and shows most fluctuation during the food crisis. During the food crisis prices jumped to extremely high levels, causing the volatility to increase as well. Figure 5 also shows the esti-
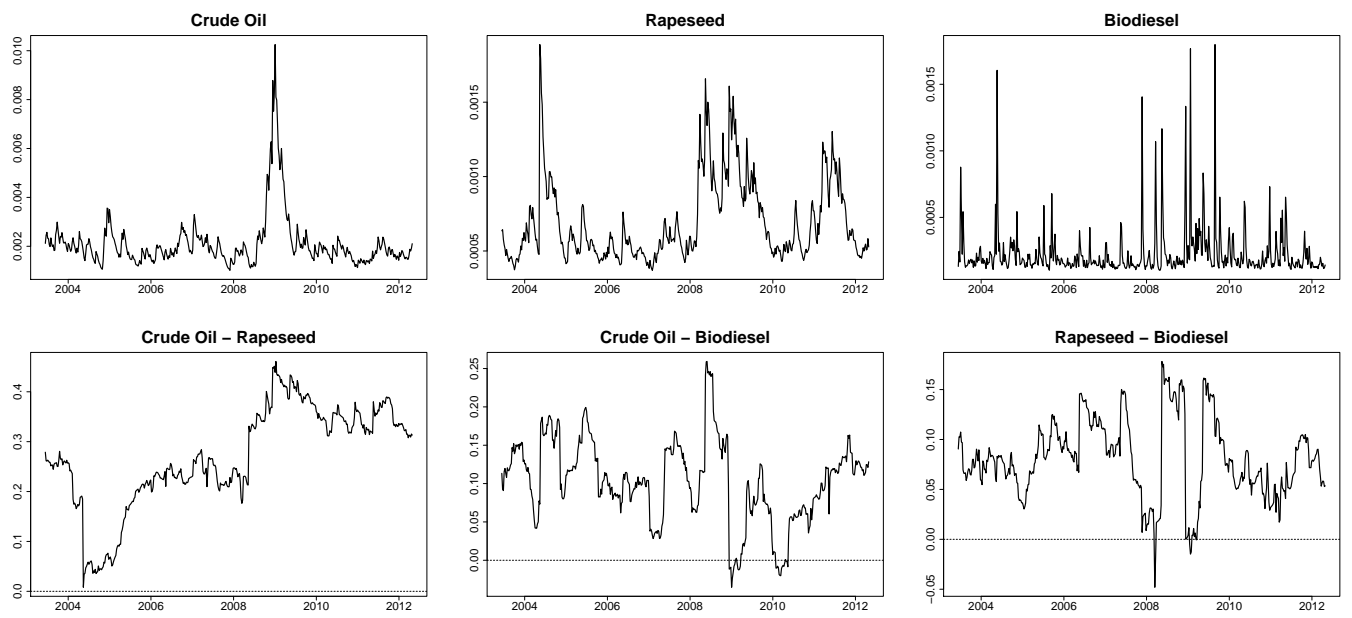

Figure 5: Conditional variance and correlation estimates.

mated conditional correlations. Again, the high persistency of market shocks can be recognized. Regarding the correlation between the volatilities of crude oil and rapeseed, it can be seen that it is strongly increasing until the end of the food crisis where it reaches a level of about 0.5. Since 2009 it is slightly decreasing and remains relatively stable. The correlations between biodiesel and crude oil and biodiesel and rapeseed are much smaller than the one between crude oil and rapeseed. Furthermore, they turn negative several times in the late 2000s. This corresponds to a time of high price levels and instability due to the global food crisis. Additionally, intensified speculative activity in the agricultural market might be responsible for 
negative correlations due to unpredictable volatility movements.

\begin{tabular}{|c|c|c|c|c|}
\hline & Crude Oil & Rapeseed & Biodiesel & DCC Parameters \\
\hline$\omega_{i}$ & -0.3442 & -0.3383 & $-4.7274 \quad(0.0009)$ & $\begin{array}{ll}a & 0.0122(0.2328)\end{array}$ \\
\hline$\alpha_{i}$ & -0.1103 & $-0.0073 \quad(0.8577)$ & $0.0879 \quad(0.3008)$ & $b \quad 0.9708(0.0000)$ \\
\hline$\beta_{i}$ & $(0.0000)$ & $0.9517 \quad(0.0000)$ & $0.4427 \quad(0.0082)$ & \\
\hline$\gamma_{i}$ & $(0.0760)$ & $0.1361 \quad(0.0651)$ & $0.5503 \quad(0.0000)$ & \\
\hline
\end{tabular}

Table 7: Estimates of the DCC-EGARCH(1,1). P-value in parentheses.

\begin{tabular}{|c|c|c|c|c|}
\hline & Crude Oil & Rapeseed & Biodiesel & DCC Parameters \\
\hline$\omega_{i}$ & -0.3041 & -0.4382 & $-4.7626 \quad(0.0000)$ & $\begin{array}{lll}a & 0.0127 & (0.2787)\end{array}$ \\
\hline$\alpha_{i}$ & -0.1061 & -0.0211 & $0.1063 \quad(0.1845)$ & $b \quad 0.9689(0.0000)$ \\
\hline$\beta_{i}$ & $0.9514 \quad(0.0000)$ & $0.9402 \quad(0.0000)$ & $0.4436 \quad(0.0009)$ & \\
\hline$\gamma_{i}$ & $0.0658 \quad(0.2448)$ & $0.1569 \quad(0.0143)$ & $0.5755 \quad(0.0000)$ & \\
\hline$\nu_{i}$ & $(0.0000)$ & $1.1129(0.0000)$ & $1.2467 \quad(0.0000)$ & \\
\hline
\end{tabular}

Table 8: Estimates of the DCC-EGARCH(1,1) model with generalized error distribution with shape parameter $\nu$. P-value in parentheses.

\subsubsection{Multivariate multiplicative volatility model estimation}

We relax the assumption of a constant unconditional covariance matrix by applying the multiplicative volatility model described in section 4.3 to the VECM residuals. In a first step the unconditional covariance matrix $\Sigma(\tau)$ is estimated nonparametrically. The likelihood cross-validation criterion yields a bandwidth parameter of 0.137. Figure 6 shows the estimated unconditional variances and correlations together with their pointwise $95 \%$ confidence interval. The confidence intervals were computed using the 0.05 and 0.95 quantiles obtained based on 200 bootstrap experiments. The plots indicate that the assumption of a constant unconditional covariance matrix is invalid.

Since the true unconditional covariance matrix cannot be observed, in order to assess the quality of the nonparametric estimates, in Figure 7 the estimated unconditional variances and correlations are shown together with the corresponding 6-month and 12-month rolling window variances and correlations. Especially with regard to the 12-month rolling covariance, the nonparametric estimates seem to fit the data quite well. The estimated long run volatility of crude oil is relatively stable except for a large peak that reaches its maximum in the beginning of 2009. This corresponds to the phase of the food crisis, where prices reached a historically high level and markets were unstable. A similar pattern can be observed in the long run volatilities of rapeseed and biodiesel. They peak during and after the food crisis and return only slowly to the pre-crisis volatility level. Crude oil reaches its pre-crisis level of volatility much faster and shows an even lower volatility at the end of the 

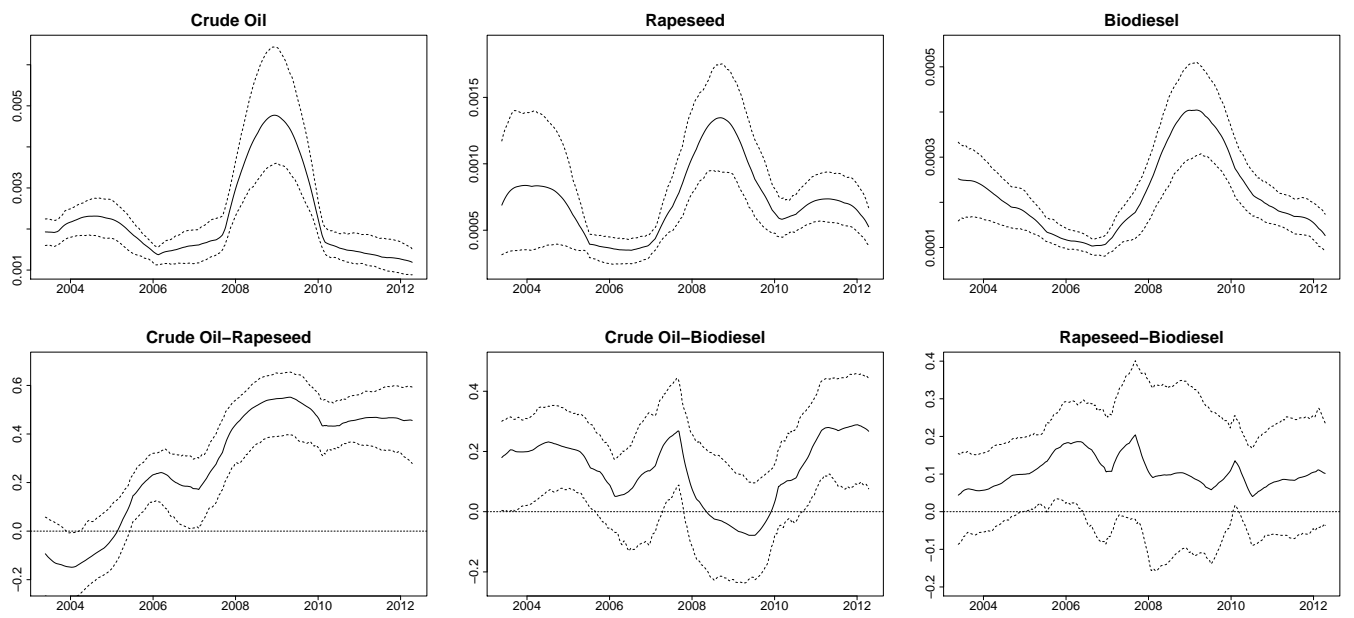

Figure 6: Unconditional variance and correlation estimates with $95 \%$ pointwise confidence intervals.
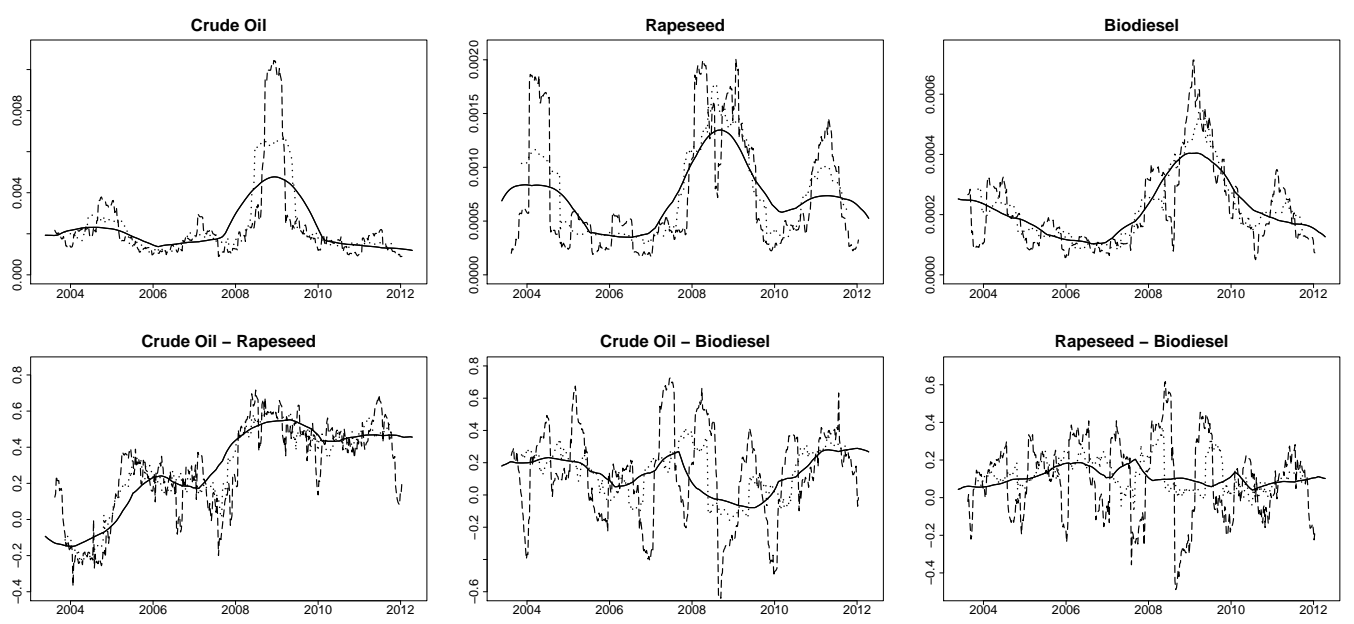

Figure 7: Unconditional variance and correlation estimates (solid line) compared to 6-month rolling window variances and correlations (dashed line) and 12-month rolling window variances and correlations (dotted line)

sample period. In none of the commodities a trend for higher volatility in prices is visible.

The unconditional correlation between the volatility of crude oil and rapeseed is insignificant in the beginning of the sample period, but shows a tendency to increase and turns significant from 2005 onwards. It increases and reaches a peak at the end of 2008, where it is about 0.5. After 2009 the correlation decreases, but still remains relatively high. The high correlation between the volatility of crude oil and the volatility of rapeseed indicates that on the one hand there is an increasing tendency to react to the same market signals. On the other hand, the simultaneous development of their volatilities may also be an indicator for volatility transmission 
between the markets. However, the direction and magnitude of such a transmission can not be derived from the utilized model. Though, since crude oil is the much larger and more international market and therefore unlikely to be influenced by the volatility of rapeseed prices, it can be assumed that part of the correlation is due to volatility spillovers from crude oil to rapeseed prices. Phases of high correlation corresponds to phases where volatilities in the crude oil and rapeseed market were especially high. This finding suggests that the correlation is highest in volatile phases, which imposes an additional market risk. This is in line with the findings of Busse et al. (2010a), who find a historically high correlation in April 2009, where their sample however ends.

The unconditional correlation estimate for biodiesel and crude oil is positive during most of the sample period. At the end of 2007 it reaches a level of about 0.3 . In 2008 it starts decreasing and turns negative in 2009. Since 2010 it is increasing again. The sudden inversion of the correlations in 2008 corresponds to the unstable phase of the food crisis. It could be an indicator for an increasing presence of speculative activity in the market, in which many see a cause of the crisis. Speculative activity can cause high price levels and lead to unpredictable volatility behavior (Robles et al., 2009). However, as already mentioned above, the effect of speculative activity is ambiguous.

The correlation between biodiesel and rapeseed is relatively low and not significant during most of the sample period. It slightly increases in the beginning of the sample period with a peak in 2006/2007. Since 2007 it stays at a low level and is insignificant during most of the remaining sample period. The peak corresponds to the time period were biofuel production in Germany boomed. From 2002 to 2007 it showed an exponential growth. Since 2007 however, biodiesel production stagnates. This is partly due to the change in the biofuel policy in Germany. Until the end of 2006 biodiesel was tax free. In 2007 tax exemptions were repealed and instead a binding minimum quote was introduced. This finding contradicts the hypothesis that biodiesel is the cause of high and volatile food prices.

In a second step the residuals of the VECM are standardized by the estimated unconditional covariance matrix. Figure 8 shows a plot of the standardized VECM residuals. The standardized residuals are tested for autocorrelation and heteroscedasticity, showing no evidence of autocorrelation nor heteroscedasticity, see Table 9. This is evidence against the presence of GARCH effects in the short run dynamics.
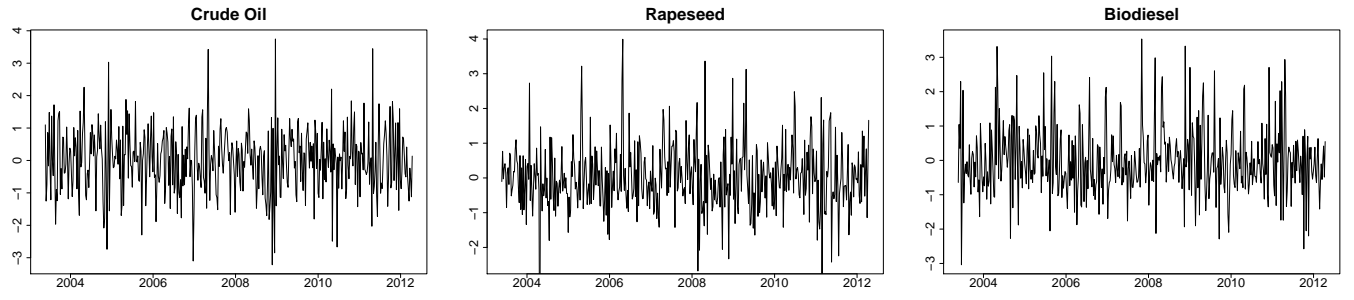

Figure 8: Residuals of the nonparametric covariance estimation 


\begin{tabular}{l|ccc|ccc}
\hline \hline & \multicolumn{3}{|c|}{ Standardized residuals } & \multicolumn{3}{c}{ Squared standardized residuals } \\
\hline \multirow{3}{*}{ Crude oil } & Test Statistic & p-Value & lags & Test Statistic & p-Value & lags \\
Rapeseed & 20.9 & 0.40 & 20 & 19.2 & 0.51 & 20 \\
Biodiesel & 18.7 & 0.54 & 20 & 23.6 & 0.26 & 20 \\
\hline \hline
\end{tabular}

Table 9: Box-Ljung test for autocorrelation of the standardized VECM residuals and the squared standardized VECM residuals

\section{Conclusion}

In this paper short and long run linkages between the volatilities of energy prices and agricultural commodity prices are studied. Specific emphasis is given to the evolution of volatilities and their correlation over time. We proposed the use of a multiplicative volatility model to capture the volatility and correlation risk structure between biodiesel, crude oil and rapeseed spot prices. The model provides a more flexible and accurate fitting procedure than the VECM with a (DCC) GARCH, by capturing a long run time varying unconditional covariance matrix, where the unconditional variance is modeled in a non-parametric way.

We find that in the long run prices move together and preserve an equilibrium relationship. However, biodiesel does not influence rapeseed and crude oil price levels in the short run and only has a limited capacity to influence rapeseed in the long run. Biodiesel prices rather react to price changes in the other two markets. Furthermore, the volatility of biodiesel is only weakly linked to the volatility of crude oil and rapeseed, while the linkage between the volatility of rapeseed and crude oil is increasing in recent years. The volatilities of rapeseed and biodiesel react to market shocks asymmetrically. Conditional correlations are mostly positive and market shocks show a high persistency. During the food crisis in 2008 conditional correlations between crude oil and biodiesel and rapeseed and biodiesel a strongly fluctuating and even turn negative at times. This can be a sign of excessive speculation in the markets. The correlation between crude oil and rapeseed volatilities is increasing in recent years, which indicates the presence of volatility spillovers. The correlations between the volatilities of biodiesel and rapeseed are low and most of the time insignificant. This reveals that biodiesel only has a reduced impact on the volatilities of rapeseed. From the perspective of our analysis, the concern that biodiesel is the cause of high and volatile food prices is unfounded. In a further study it would be interesting to investigate the direction and size of potential spill over effects.

\section{References}

Balcombe K, Rapsomanikis G. 2008. Bayesian estimation and selection of nonlinear vector error correction models: the case of the sugar-ethanol-oil nexus in brazil. American Journal of Agricultural Economics 90: 658-668. DOI: 10.1111/j.14678276.2008.01136.x. 
Bauwens L, Hafner C, Pierret D. 2012. Multivariate volatility modeling of electricity futures. Journal of Applied Econometrics 28. DOI: 10.1002/jae.2280.

Bauwens L, Laurent S, Rombouts J. 2006. Multivariate garch models: a survey. Journal of Applied Econometrics 21: 79-109. DOI: 10.1002/jae.842.

Bowman A, Azzalini A. 1997. Applied smoothing techniques for data analysis. Oxford University Press, USA.

Busse S, Bruemmer B, Ihle R. 2010a. Investigating rapeseed price volatilities in the course of the food crisis. Schriften der Gesellschaft für Wirtschafts-und Sozialwissenschaften des Landbaus eV Band 46 : 275.

Busse S, Brummer B, Ihle R. 2010b. The pattern of integration between fossil fuel and vegetable oil markets: The case of biodiesel in germany. In 2010 Annual Meeting, July 25-27, 2010, Denver, Colorado, 1010. Agricultural and Applied Economics Association.

Campbell J, Perron P. 1991. Pitfalls and opportunities: what macroeconomists should know about unit roots. In NBER Macroeconomics Annual 1991, volume 6. MIT Press, 141-220.

Du X, McPhail L. 2012. Inside the black box: the price linkage and transmission between energy and agricultural markets. The Energy Journal 33: 171-194. DOI: 10.5547/01956574.33.2.8.

EBB. 2008. An economic and security of supply analysis of the widening eu diesel deficit. EBB Factsheet .

Engle R, Granger C. 1987. Co-integration and error correction: representation, estimation, and testing. Econometrica: Journal of the Econometric Society 55: $251-276$.

Engle R, Sheppard K. 2001. Theoretical and empirical properties of dynamic conditional correlation multivariate garch. Technical report, National Bureau of Economic Research .

Ghosh J. 2010. The unnatural coupling: Food and global finance. Journal of Agrarian Change 10: 72-86. DOI: 10.1111/j.1.

Granger C. 1981. Some properties of time series data and their use in econometric model specification. Journal of Econometrics 16: 121-130. DOI: 10.1016/03044076(81)90079-8.

Hafner C, Linton O. 2010. Efficient estimation of a multivariate multiplicative volatility model. Journal of Econometrics 159: 55-73. DOI: 10.1016/j.jeconom.2010.04.007.

Hamilton J. 1994. Time series analysis, volume 2. Cambridge University Press. 
Härdle W, López Cabrera B, Okhrin O, Wang W. 2011. Localising temperature risk. Working paper, SFB 649 Humboldt Universität zu Berlin .

Hassouneh I, Serra T, Goodwin BK, Gil JM. 2012. Non-parametric and parametric modeling of biodiesel, sunflower oil, and crude oil price relationships. Energy Economics 34: 1507-1513. DOI: 10.1016/j.eneco.2012.06.027.

Headey D, Fan S. 2008. Anatomy of a crisis: the causes and consequences of surging food prices. Agricultural Economics 39: 375-391. DOI: 10.1111/j.15740862.2008.00345.x.

Johansen S. 1995. Likelihood-based inference in cointegrated vector autoregressive models. Oxford University Press.

Kristoufek L, Janda K, Zilberman D. 2012. Correlations between biofuels and related commodities before and during the food crisis: A taxonomy perspective. Energy Economics 34: 1380-1391. DOI: 10.1016/j.eneco.2012.06.016.

Kwiatkowski D, Phillips P, Schmidt P, Shin Y. 1992. Testing the null hypothesis of stationarity against the alternative of a unit root: How sure are we that economic time series have a unit root? Journal of Econometrics 54: 159-178. DOI: 10.1016/0304-4076(92)90104-Y.

Lamers P. 2011. International biodiesel markets - development in production and trade. UFOP Schriften .

LEL, LfL. 2012. Agrarmärkte 2011/2012.

Liu X, Filler G, Odening M. 2012. Testing for speculative bubbles in agricultural commodity prices: A regime switching approach. In 123rd Seminar, February 23-24, 2012, Dublin, Ireland. European Association of Agricultural Economists.

Long X, Su L, Ullah A. 2011. Estimation and forecasting of dynamic conditional covariance: A semiparametric multivariate model. Journal of Business and Economic Statistics 29: 109-125. DOI: 10.1198/jbes.2009.07057.

Lütkepohl H. 2005. New introduction to multiple time series analysis. SpringerVerlag.

Myers R. 1994. Time series econometrics and commodity price analysis: a review. Review of Marketing and Agricultural Economics 62: 167-182.

Nelson D. 1991. Conditional heteroskedasticity in asset returns: a new approach. Econometrica: Journal of the Econometric Society 59: 347-370. DOI: 10.2 $307 / 2938260$.

OECD-FAO. 2009. Oecd-fao agricultural outlook, 2009-2018 DOI: 10.1787/agr_outlook-2009-en.

Rathmann R, Szklo A, Schaeffer R. 2010. Land use competition for production of food and liquid biofuels: An analysis of the arguments in the current debate. Renewable Energy 35: 14-22. DOI: 10.1016/j.renene.2009.02.025. 
Robles M, Torero M, Von Braun J. 2009. When speculation matters. International Food Policy Research Institute, Issue Brief 57.

Serra T. 2011. Volatility spillovers between food and energy markets: A semiparametric approach. Energy Economics 33: 1155-1164. DOI: 10.1016/j.eneco.2011.04.003.

Serra T, Zilberman D, Gil J. 2011. Price volatility in ethanol markets. European Review of Agricultural Economics 38: 259-280. DOI: 10.1093/erae/jbq046.

Silvennoinen A, Teräsvirta T. 2009. Multivariate garch models. Handbook of Financial Time Series : 201-229DOI: 10.1007/978-3-540-71297-89.

Sorda G, Banse M, Kemfert C. 2010. An overview of biofuel policies across the world. Energy Policy 38: 6977-6988. DOI: 10.1016/j.enpol.2010.06.066.

Trujillo-Barrera A, Mallory M, Garcia P. 2011. Volatility spillovers in the US crude oil, corn, and ethanol markets. In Proceedings of the NCCC-134 Conference on Applied Commodity Price Analysis, Forecasting, and Market Risk Management. St. Louis, MO.

Tse Y, Tsui A. 2002. A multivariate generalized autoregressive conditional heteroscedasticity model with time-varying correlations. Journal of Business and Economic Statistics 20: 351-362. DOI: 10.1198/073500102288618496.

Yin J, Geng Z, Li R, Wang H. 2010. Nonparametric covariance model. Statistica Sinica 20: 469.

Zhang Z, Lohr L, Escalante C, Wetzstein M. 2009. Ethanol, corn, and soybean price relations in a volatile vehicle-fuels market. Energies 2: 320-339. DOI: $10.3390 /$ en20200320. 


\section{SFB 649 Discussion Paper Series 2013}

For a complete list of Discussion Papers published by the SFB 649, please visit http://sfb649.wiwi.hu-berlin.de.

001 "Functional Data Analysis of Generalized Quantile Regressions" by Mengmeng Guo, Lhan Zhou, Jianhua Z. Huang and Wolfgang Karl Härdle, January 2013.

002 "Statistical properties and stability of ratings in a subset of US firms" by Alexander B. Matthies, January 2013.

003 "Empirical Research on Corporate Credit-Ratings: A Literature Review" by Alexander B. Matthies, January 2013.

004 "Preference for Randomization: Empirical and Experimental Evidence" by Nadja Dwenger, Dorothea Kübler and Georg Weizsäcker, January 2013.

005 "Pricing Rainfall Derivatives at the CME" by Brenda López Cabrera, Martin Odening and Matthias Ritter, January 2013.

006 "Inference for Multi-Dimensional High-Frequency Data: Equivalence of Methods, Central Limit Theorems, and an Application to Conditional Independence Testing" by Markus Bibinger and Per A. Mykland, January 2013.

007 "Crossing Network versus Dealer Market: Unique Equilibrium in the Allocation of Order Flow" by Jutta Dönges, Frank Heinemann and Tijmen R. Daniëls, January 2013.

008 "Forecasting systemic impact in financial networks" by Nikolaus Hautsch, Julia Schaumburg and Melanie Schienle, January 2013.

009 "'I'll do it by myself as I knew it all along': On the failure of hindsightbiased principals to delegate optimally" by David Danz, Frank Hüber, Dorothea Kübler, Lydia Mechtenberg and Julia Schmid, January 2013.

010 "Composite Quantile Regression for the Single-Index Model" by Yan Fan, Wolfgang Karl Härdle, Weining Wang and Lixing Zhu, February 2013.

011 "The Real Consequences of Financial Stress" by Stefan Mittnik and Willi Semmler, February 2013.

012 "Are There Bubbles in the Sterling-dollar Exchange Rate? New Evidence from Sequential ADF Tests" by Timo Bettendorf and Wenjuan Chen, February 2013.

013 "A Transfer Mechanism for a Monetary Union" by Philipp Engler and Simon Voigts, March 2013.

014 "Do High-Frequency Data Improve High-Dimensional Portfolio Allocations?" by Nikolaus Hautsch, Lada M. Kyj and Peter Malec, March 2013.

015 "Cyclical Variation in Labor Hours and Productivity Using the ATUS" by Michael C. Burda, Daniel S. Hamermesh and Jay Stewart, March 2013.

016 "Quantitative forward guidance and the predictability of monetary policy - A wavelet based jump detection approach -" by Lars Winkelmann, April 2013.

017 "Estimating the Quadratic Covariation Matrix from Noisy Observations: Local Method of Moments and Efficiency" by Markus Bibinger, Nikolaus Hautsch, Peter Malec and Markus Reiss, April 2013.

018 "Fair re-valuation of wine as an investment" by Fabian Y.R.P. Bocart and Christian M. Hafner, April 2013.

019 "The European Debt Crisis: How did we get into this mess? How can we get out of it?" by Michael C. Burda, April 2013.

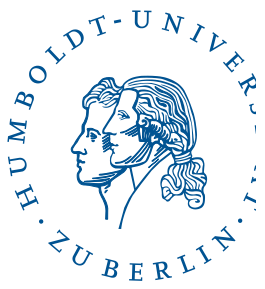




\title{
SFB 649 Discussion Paper Series 2013
}

\author{
For a complete list of Discussion Papers published by the SFB 649, \\ please visit http://sfb649.wiwi.hu-berlin.de.
}

020 "Disaster Risk in a New Keynesian Model" by Maren Brede, April 2013.

021 "Econometrics of co-jumps in high-frequency data with noise" by Markus Bibinger and Lars Winkelmann, May 2013.

022 "Decomposing Risk in Dynamic Stochastic General Equilibrium" by Hong Lan and Alexander Meyer-Gohde, May 2013.

023 "Reference Dependent Preferences and the EPK Puzzle" by Maria Grith, Wolfgang Karl Härdle and Volker Krätschmer, May 2013.

024 "Pruning in Perturbation DSGE Models - Guidance from Nonlinear Moving Average Approximations" by Hong Lan and Alexander Meyer-Gohde, May 2013.

025 "The 'Celtic Crisis': Guarantees, transparency, and systemic liquidity risk" by Philipp König, Kartik Anand and Frank Heinemann, May 2013.

026 "State Price Densities implied from weather derivatives" by Wolfgang Karl Härdle, Brenda López-Cabrera and Huei-Wen Teng, May 2013.

027 "Bank Lending Relationships and the Use of Performance-Sensitive Debt" by Tim R. Adam and Daniel Streitz, May 2013.

028 "Analysis of Deviance in Generalized Partial Linear Models" by Wolfgang Karl Härdle and Li-Shan Huang, May 2013.

029 "Estimating the quadratic covariation of an asynchronously observed semimartingale with jumps" by Markus Bibinger and Mathias Vetter, May 2013.

030 "Can expert knowledge compensate for data scarcity in crop insurance pricing?" by Zhiwei Shen, Martin Odening and Ostap Okhrin, May 2013.

031 "Comparison of Methods for Constructing Joint Confidence Bands for Impulse Response Functions" by Helmut Lütkepohl, Anna StaszewskaBystrova and Peter Winker, May 2013.

032 "CDO Surfaces Dynamics" by Barbara Choroś-Tomczyk, Wolfgang Karl Härdle and Ostap Okhrin, July 2013.

033 "Estimation and Inference for Varying-coefficient Models with Nonstationary Regressors using Penalized Splines" by Haiqiang Chen, Ying Fang and Yingxing Li, July 2013.

034 "Robust Estimation and Inference for Threshold Models with Integrated Regressors" by Haiqiang Chen, July 2013.

035 "A new perspective on the economic valuation of informal care: The wellbeing approach revisited" by Konstantin Kehl and Stephan Stahlschmidt, July 2013.

036 "Herding in financial markets: Bridging the gap between theory and evidence" by Christopher Boortz, Simon Jurkatis, Stephanie Kremer and Dieter Nautz, July 2013.

037 "Default Risk Calculation based on Predictor Selection for the Southeast Asian Industry" by Wolfgang Karl Härdle and Dedi Dwi Prastyo, August 2013.

038 "ECB monetary policy surprises: identification through cojumps in interest rates" by Lars Winkelmann, Markus Bibinger and Tobias Linzert, August 2013.

039 "Limited higher order beliefs and the welfare effects of public information" by Camille Cornand and Frank Heinemann, August 2013.

040 "Privacy Concerns, Voluntary Disclosure of Information, and Unraveling: An Experiment" by Volker Benndorf, Dorothea Kübler and Hans-Theo Normann, September 2013.

\section{SFB 649, Spandauer Straße 1, D-10178 Berlin http://sfb649.wiwi.hu-berlin.de}

This research was supported by the Deutsche

Forschungsgemeinschaft through the SFB 649 "Economic Risk".

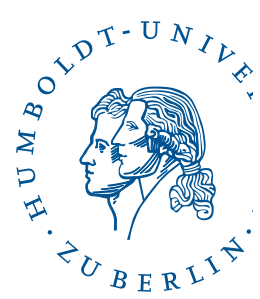




\section{SFB 649 Discussion Paper Series 2013}

For a complete list of Discussion Papers published by the SFB 649, please visit http://sfb649. wiwi.hu-berlin.de.

041 "Goodness-of-fit Test for Specification of Semiparametric Copula Dependence Models" by Shulin Zhang, Ostap Okhrin, Qian M. Zhou and Peter X.-K. Song, September 2013.

042 "Volatility linkages between energy and agricultural commodity prices" by Brenda López Cabrera and Franziska Schulz, September 2013.

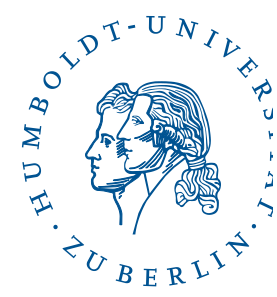

